\title{
Perfil ideal do professor do século XXI
}

\author{
Ideal profile of the 21 st century teacher \\ Ideal profile of the 21st century teacher
}

Recebido: 20/05/2021 | Revisado: 28/05/2021 | Aceito: 01/06/2021 | Publicado: 11/06/2021

\author{
Dayvane Oliveira da Silva \\ ORCID: https://orcid.org/0000-0002-2563-3977 \\ Escola: Complexo Educacional de Ensino Fundamental, Brasil \\ E-mail:dayvane@hotmail.com \\ Ronielle Batista Oliveira Santos \\ ORCID: https://orcid.org/0000-0002-0416-0349 \\ Escola Municipal José Almeida Monteiro, Brasil \\ E-mail: ronniellebatista@gmail.com \\ Nívia Rodrigues de Queiroz \\ ORCID: https://orcid.org/0000-0002-4211-2057 \\ Universidade Federal do Tocantins, Brasil \\ E-mail: niviadez@mail.uft.edu.br
}

\begin{abstract}
Resumo
Falar de educação na atualidade é quase impossível sem falar nas inúmeras transformações ocorridas ao longo dos anos, transformações essas que tem demandado um esforço extra daqueles que fazem ela acontecer "o professor". O professor muitas vezes precisa se reinventar para conseguir acompanhar uma sociedade em transformações diárias e todas essas transformações em especial no campo educacional tem gerado inquietações na busca de uma melhor qualidade na relação do professor com o processo de ensino aprendizagem. Ensinar na atualidade é um desafio de proporções gigantescas, tem muito mais haver com a formação do cidadão do que com a transmissão de conteúdos prontos e acabados, acredito que essa tenha sido a principal mudança no campo educacional quando nos referimos a prática docente. Mas afinal o que o professor do século XXI deve ter para se encaixar nesse novo modelo de sociedade? A leitura deste artigo permitirá uma reflexão sobre esse perfil ideal de professor.
\end{abstract}

Palavras-chave: Professor; Competências; Ação docente; Perfil ideal.

\begin{abstract}
Speaking of education today is almost impossible not to mention the countless changes that have taken place over the years, which have demanded an extra effort from those who make it happen "the teacher". The teacher often needs to reinvent himself in order to be able to accompany a society in daily transformations and all these transformations, especially in the educational field, have generated concerns in the search for a better quality in the teacher's relationship with the teaching-learning process. Teaching today is a challenge of gigantic proportions, it has much more to do with the education of the citizen than with the transmission of ready and finished content, I believe that this has been the main change in the educational field when we refer to teaching practice. But after all, what should the 21 st century teacher has to fit into this new model of society? Reading this article will allow a reflection on this ideal teacher profile.
\end{abstract}

Keywords: Teacher; Skills; Teaching action; Ideal profile.

\section{Resumen}

Hablar de educación hoy en día es casi imposible sin mencionar los innumerables cambios que se han producido a lo largo de los años, que han requerido un esfuerzo extra por parte de quienes lo hacen realidad "el maestro". El docente muchas veces necesita reinventarse para poder acompañar a una sociedad en las transformaciones cotidianas y todas estas transformaciones, especialmente en el ámbito educativo, han generado inquietudes en la búsqueda de una mejor calidad en la relación del docente con el proceso de enseñanza-aprendizaje. La enseñanza hoy es un desafío de proporciones gigantescas, tiene mucho más que ver con la educación del ciudadano que con la transmisión de contenidos listos y terminados, creo que este ha sido el principal cambio en el campo educativo cuando nos referimos a la práctica docente. Pero después de todo, ¿qué debería tener el maestro del siglo XXI para encajar en este nuevo modelo de sociedad? La lectura de este artículo nos permitirá reflexionar sobre este perfil de profesor ideal.

Palabras clave: Profesor; Habilidades; Acción docente; Perfil ideal. 


\section{Introdução}

É inegável a importância do professor para o desenvolvimento pleno de uma sociedade, assim também como é inegável o quão difícil tem se tornado a cada dia o fazer docente, se adequar a todas essas inovações tecnológicas, mudanças de comportamento, regras e tantas outras coisas não tem sido uma tarefa fácil para os professores, estes se veem diante de duas alternativas, se adequar a essa nova realidade ou permanecer preso em práticas passadas.

Se voltarmos ao século passado essa tarefa se torna ainda mais difícil, pois em boa parte do tempo as maiores preocupações do professor era a mera transmissão de conhecimentos. O século XXI está sendo marcado por transformações significativas no campo educacional, principalmente no papel do professor que passa de um transmissor do conhecimento para um mediador da aprendizagem.

No passado para ser considerado um bom professor bastava dominar os conteúdos a serem ensinados, administrando e avaliando a turma com certa rigidez e autoritarismo, em contrapartida a esse modelo ideal de professor o século XXI traz um modelo mais dinâmico, criativo, onde o principal papel é levar o seu aluno a pensar criticamente para que assim seja participante ativo da sociedade.

Outro ponto que merece destaque ao se falar da profissão professor é o fato da desvalorização da mesma, poucos são os que querem ser professor nos dias atuais e isso se deve a inúmeros fatores desde os financeiros até aos emocionais, fato esse preocupante pois tratamos aqui da profissão que forma todas as outras, e o que seria da sociedade se não fosse os professores?

Diante de tantas inovações se reinventar a cada dia tem sido um dos principais desafios para alguns professores, falo alguns porque infelizmente muitos se acomodaram e permanecem presos no século passado e se recusam a mudar suas práticas didáticas, prejudicando assim os mais interessados no desenvolvimento educacional "o aluno".

\section{Metodologia}

Essa pesquisa se caracteriza como bibliográfica, a princípio foi feito um levantamento bibliográfico e análise de documentos que pudessem servir como base para nossos estudos. Para que a pesquisa pudesse ser seguida foram consultados livros, artigos científicos e revistas que tratassem do tema em questão, também foram incluídos alguns entendimentos pessoais do dia a dia de alguns profissionais de educação.

O intuito de uma pesquisa bibliográfica é colocar o cientista em contato com o que foi produzido sobre determinado assunto, inclusive através de conferências (Lakatos \& Marconi, 1996).

Para que pudéssemos ter um entendimento mais apurado do tema, foi necessário buscas em várias fontes de natureza diversa, para que chegássemos a um ponto mais seguro do objeto pesquisado.

De acordo com Gil (1994, p. 71) "A principal vantagem da pesquisa bibliográfica reside no fato de permitir ao investigador a cobertura de uma gama de fenômenos muito mais ampla do que aquela que poderia pesquisar diretamente".

\section{Perfil ideal do Professor do Século XXI}

Ao longo do tempo o campo educacional foi sendo afetado por diversas mudanças e uma das principais, com certeza, afetou diretamente o professor. Sabe-se que todas essas mudanças, até o momento, não têm sido fáceis de serem enfrentadas, uma vez que se comparadas com o perfil do professor no passado são mudanças bastante significativas. Se adequar a todas essas mudanças requer muito mais que tempo, mas também força de vontade do professor em buscar se adaptar às novas demandas da educação.

Ser um bom professor nos dias atuais requer muito mais que conhecimentos específicos das disciplinas, o professor precisa ter um rol de práticas de ensino que atenda a cada necessidade de sua turma e que prepare o aluno para ser um cidadão 
capaz de mudar a realidade em que vive. O professor Nóvoa (1995) diz que "os professores precisam reencontrar novos valores, novos idealismos escolares que permitam atribuir um novo sentido a ação docente", de fato esse é um dos maiores desafios na educação da atualidade, se reinventar para uma sociedade que vive em constante transformação.

A demanda da sociedade hoje exige que os professores sejam cada vez mais "humanos" e isso exige muita paciência e cautela, pois as mudanças se deram em todos os aspectos e o que mais mudou de fato foi o próprio comportamento do aluno, que hoje se tornou mais agressivo e cheio de doenças chamadas sociais, o que tem exigido extremo cuidado no ato de lidar com os alunos, esse fato tem exigido no professor o desenvolvimento de algumas atitudes que têm auxiliando o seu trabalho em sala de aula.

É interessante perceber que não existe uma receita pronta para ser um bom professor, pois cada um tem seu modo e suas particularidades, no entanto existem algumas características que devem ser comuns a todos eles, como exemplo posso citar, senso de justiça, flexibilidade, criatividade, dedicação, respeito às diferenças e compromisso com o ato de educar, sem essas características dificilmente o professor conseguirá êxito em sua prática pedagógica.

Alguns estudos mostram competências necessárias para o bom desenvolvimento do processo de ensino aprendizagem.

1. Organizar e dirigir situações de aprendizagem.

2. Administrar a progressão das aprendizagens.

3. Conceber e fazer evoluir os dispositivos de diferenciação.

4. Envolver os alunos em suas aprendizagens e em seu trabalho.

5. Trabalhar em equipe.

6. Participar da administração da escola.

7. Informar e envolver os pais.

8. Utilizar novas tecnologias.

9. Enfrentar os deveres e os dilemas éticos da profissão.

10. Administrar sua própria formação contínua. (Perrenoud, 2000, p.12;13)

Essas competências segundo Perrenoud (2000) servem para delinear o trabalho docente, mas isso só será possível se os professores se dispuserem a estudar as mesmas e saírem do comodismo que muitos se encontram e as colocarem em prática, isso acontecendo, com certeza, além de facilitar o seu trabalho promoverá uma educação de mais qualidade.

O século XXI com todas as suas inovações têm exigido cada vez mais novas competências e habilidades aos professores, e essas competências e habilidades não devem estar relacionadas somente a conteúdos como também a desenvolvimento de valores e atitudes que permitam ao aluno seu desenvolvimento completo, essa talvez seja a principal exigência ao professor, pois agora além de se preocupar com a transmissão de conteúdos o professor deve também desenvolver atitudes nos alunos que vão além do livro didático.

É necessário rejeitar os sistemas de aprendizagem que alienam o indivíduo e o tratam como uma mercadoria e as práticas sociais que dividem e desumanizam os povos. Desenvolver uma educação inspirada em valores e princípios é de importância crucial para se atingir um desenvolvimento durável e pacífico (Unesco, 2015, p. 40).

É comum ouvirmos falar que a responsabilidade dos pais foram transferidas as escolas e consequentemente aos professores, de fato isso tem sua verdade, vemos a cada dia a família depositando seus filhos nas escolas e direcionando a educação dos filhos aos professores, que em sua maioria não tem atendido essa demanda o que tem gerado frutos negativos para a sociedade. Essa falta de acompanhamento dos pais na educação dos filhos também se deve a todas essas transformações, o tempo tem sido inimigo de muitos, que precisam se desdobrar entre as responsabilidades de ter uma família e conciliar com trabalhos e outras coisas, o que não justifica deixar a educação dos filhos por conta da escola, mas que sabemos que na maioria das vezes são as desculpas usadas pelos pais que não conseguem se fazer presentes na educação dos filhos. 
Uma ligação estreita e contínua entre os professores e os pais leva, pois a muita coisa que a uma informação mútua: este intercâmbio acaba resultando em ajuda recíproca e, frequentemente, em aperfeiçoamento real dos métodos. Ao aproximar a escola da vida ou das preocupações profissionais dos pais, e ao proporcionar, reciprocamente, aos pais um interesse pelas coisas da escola chega-se até mesmo a uma divisão de responsabilidades (Piaget. 2007, p.50)

Tudo mudou e para conseguir se adequar a essa realidade o professor deve levar em conta os quatro pilares básicos da educação: aprender a conhecer; aprender a fazer; aprender a viver juntos e aprender a ser, esses pilares são as bases que devem orientar a educação e consequentemente o trabalho docente.

Vamos analisar cada um dos pilares que norteiam o trabalho de um bom professor:

Aprender a conhecer - a aquisição de conteúdos é menos válida e o que mais importa é domínio dos instrumentos do conhecimento. Neste pilar é importante desenvolver no aluno a compreensão do mundo que o rodeia, despertando o desejo de aprender de diferentes formas. "Um animador que desafia seus alunos, que os incite a pesquisa, que possa desequilibrá-los em suas certezas, para levá-los a procura, a busca, a reconstituição do equilíbrio desestabilizado” (Antunes, 2012, p. 20).

Aprender a fazer - apesar de estar intimamente ligado a anterior, esse tem muito mais haver com a formação profissional do aluno, como ensinar o aluno a pôr o conhecimento adquirido em prática é o principal foco deste pilar. “Aprender a fazer é, portanto, captar o espírito da estratégia e da reflexibilidade, que permitem um refazer contínuo do agir à medida que os dados oferecidos pelo ambiente o pedem e exigem" (Libânio, 2012, 102).

Aprender a viver juntos - temos aqui o maior desafio da educação atual, que é desenvolver uma educação onde o respeito, a tolerância, a empatia, sejam pontos de partida de qualquer relacionamento social. "O caminho da autêntica formação para viver juntos passa por uma dupla descoberta: a do valor próprio e a do valor dos outros” (Libânio, 2012, p. 122).

Aprender a ser - aprender a ser autônomo, crítico, criativo e acima de tudo o aluno deve saber valorizar seu potencial diante da sociedade. "A educação deve propor como uma de suas finalidades essenciais o desenvolvimento total do indivíduo, espírito e corpo, sensibilidade, sentido estético, responsabilidade pessoal e espiritualidade” (Antunes, 2010, p.71).

Esses quatro pilares devem de fato orientar o professor na busca por um perfil ideal, sem o conhecimento deles dificilmente se conseguirá uma formação completa em nossos educandos, uma vez que os mesmos supõem uma educação que supera a transmissão de conhecimentos e busca uma formação nos educandos em todas as esferas, intelectual, social, pessoal e a emocional.

\subsection{Prática docente}

Falar da prática docente não é tarefa fácil e exige uma certa cautela, sabe-se que muitos professores ainda têm práticas consideradas ultrapassadas para a realidade em que vivemos, infelizmente muitos ainda não aceitam as mudanças impostas por tantas transformações e acabam presos no passado o que em geral não tem funcionado quando se quer uma educação voltada para a formação completa do educando.

Muitas práticas educativas por serem ultrapassadas acabam criando uma espécie de barreira entre professor e aluno, o que dificulta o processo de ensino aprendizagem nas escolas. Esse é um problema que precisa ser encarado com seriedade pelos envolvidos, se já não está sendo tarefa fácil educar nos dias atuais, imaginemos agora como fica quando não se tem um bom relacionamento entre os principais envolvidos no processo.

A prática educativa de cada professor é sim um ponto que merece destaque quando resolve-se falar no perfil de um professor ideal, pois a prática docente funciona com a identidade do professor em uma sociedade, e precisa ainda ser vista até mesmo pelos professores com algo importante e que determinará muito do que eles conseguirão na formação de seus alunos. 
A reflexão sobre a prática não resolve tudo, a experiência refletida não resolve tudo. São necessárias estratégias, procedimentos, modos de fazer, além de uma sólida cultura geral, que ajudam a melhor realizar o trabalho e melhorar a capacidade reflexiva sobre o que e como mudar (Libânio, 2005, p. 76)

A BNCC - Base Nacional Comum Curricular traz 10 competências a serem trabalhadas em sala de aula e dessas tem algumas que estão intimamente ligadas à afetividade, que hoje é uma das principais competências que o professor deve ter para se encaixar nesse novo modelo de educação.

Trabalhar com afetividade não é tarefa para todos e quanto mais antigo for o professor mais difícil se torna desenvolver essa habilidade, contudo não se deve deixar de lado esse importante aliado do trabalho docente, pois segundo estudiosos a afetividade é sim um meio seguro para se chegar ao alvo principal: o aluno.

Como prática estritamente humana jamais pude entender a educação como experiência fria, sem alma, em que os sentimentos e as emoções, os desejos, os sonhos devessem ser reprimidos por uma espécie de ditadura racionalista. Nem tampouco jamais compreendi a prática educativa como uma experiência a que faltasse rigor em que se gera a necessária disciplina intelectual (Freire, 1996, p. 146).

Ser professor na atualidade é sim ser de tudo um pouco, é entender além de práticas educativas e de conteúdos mais também de vida, de ser humano, é ser capaz de parar conteúdos importantes para falar de acontecimentos reais que de certa forma impactam a sociedade. Com tantos acontecimentos ruins dentro de nossas escolas, levar nossos alunos a pensarem sobre todas essas mazelas que nos assolam é muito mais que simplesmente educar, é educar para a vida e educar para a vida sem uma pitada de afetividade é tarefa praticamente impossível.

\subsection{Qualidades de um bom professor}

Em outubro de 2010 a revista Nova Escola publicou uma matéria intitulada "20 qualidades do professor ideal" e nessa leitura percebe-se que são exatamente essas qualidades que o bom professor deve ter para desenvolver suas atividades docentes com êxito.

O docente ideal:

1. Domina os conteúdos curriculares das disciplinas;

2. Tem os conteúdos curriculares das disciplinas;

3. Conhece as didáticas das disciplinas;

4. Domina as diretrizes curriculares das disciplinas;

5. Organiza os objetivos e conteúdos de maneira coerente com o currículo, o desenvolvimento dos estudantes e seu nível de aprendizagem;

6. Seleciona recursos de aprendizagem de acordo com os objetivos de aprendizagem e as características de seus alunos;

7. Escolhe estratégias de avaliação coerentes com os objetivos de aprendizagem;

8. Estabelece um clima favorável para a aprendizagem;

9. Manifesta altas expectativas em relação às possibilidades de aprendizagem de todos;

10. Institui e mantém normas de convivência em sala;

11. Demonstra e promove atitudes e comportamentos positivos;

12. Comunica-se efetivamente com os pais de alunos;

13. Aplica estratégias de ensino desafiantes;

14. Utiliza métodos e procedimentos que promovem o desenvolvimento do pensamento autônomo; 15 . Otimiza o tempo disponível para o ensino; 
16. Avalia e monitora a compreensão dos conteúdos;

17. Busca aprimorar seu trabalho constantemente com base na reflexão sistemática, na autoavaliação e no estudo;

18. Trabalhar em equipe;

19. Possui informação atualizada sobre as responsabilidades de sua profissão;

20. Conhece o sistema educacional e as políticas vigentes. (Nova escola edição 236, 01 de outubro | 2010).

Observa-se que o professor deve ter um novo olhar sobre o processo educacional, isso implica em todos os processos necessários para a concretização da aprendizagem, desde as metodologias de ensino até aos meios de avaliação, o que tem exigido cada vez mais empenho na busca por novos saberes por parte dos professores. Ressalto aqui a importância da gestão escolar em dar suporte para os professores em sua prática docente, a escola deve ter como ponto de partida a união entre suas partes e jamais negar o acompanhamento ao professor, que sozinho tão pouco conseguirá lograr êxito em sua prática.

Outro ponto que merece destaque quando tratamos do professor ideal é a própria formação, seja a docente ou a continuada, essas devem ter como base esse novo olhar da educação para que assim o professor não chegue em sala de aula e se depare com uma realidade diferente da que lhe foi apresentada em suas formações.

Segundo Freire (1975), o educador e o educando aprendem juntos nessa nova perspectiva de educação, ou seja, deparamo-nos hoje com uma educação onde se aprende e se ensina concomitantemente, tarefa difícil principalmente para os professores do século passado que se encontram inseridos nessa nova realidade, pois isso tudo impacta além de sua prática sua própria formação pedagógica.

Se nos voltarmos para analisar a realidade que vivemos com um olhar futurista, perceberemos que o professor é uma das peças principais para conseguir mudar essa realidade, no entanto veremos também que hoje a maioria dos professores são doentes, sejam de doenças que afetam o corpo físico ou doenças que afetam a alma, o emocional. É comum ver professores revoltados com a situação em que vivem, salários baixos, condições mínimas para realizar um bom trabalho, ameaças constantes de alunos e até mesmo de pais, e como não poderia deixar de ser isso acaba por refletir nos resultados de sua prática docente.

As qualidades de um bom professor estão intimamente ligadas com as condições que os mesmos são submetidos em sua prática, afinal é muito mais fácil ser um bom professor em uma escola onde se tem espaço adequado, quantidade de alunos limite em sala, salas climatizadas, recursos a sua disposição, gestão democrática e por fim, mas não menos importante a participação efetiva da família na educação dos filhos do que em uma escola onde nada disso acontece. Suas qualidades também estão ligadas aos salários que como sabemos é um descaso em nosso país, esse é um dos principais fatores que desmotivam os professores e consequentemente fazem sua qualidade enquanto educador cair.

Apesar de todas as mazelas que assolam a educação em nosso país ainda acredito que a educação é o caminho para conseguirmos mudança em um futuro e que o caminho no momento é tentar sensibilizar nossos professores para que consigam ver a educação como algo que merece cada vez mais nosso empenho e dedicação e que apesar das baixas remunerações a que são submetidos não devem deixar de fazer um trabalho com excelência na educação do futuro de nossa nação, por que é isso que os alunos de hoje são, o futuro da nação.

\section{A Formação do Professor Ideal}

Não dá para falar em um bom professor sem mencionar a formação que esses professores passam nas universidades, sabe-se que a profissão de professor está de certa forma banalizada e que muitos ingressam na carreira docente muitas vezes por falta de opção e com isso acabam fazendo um trabalho em sala de aula de qualquer jeito. 
É comum vermos em cidades pequenas cursos de graduação que acontecem quinzenalmente, principalmente na área docente por serem cursos mais baratos, de certa forma isso tem produzido profissionais sem qualificações adequadas para o ato de ensinar. Os cursos de graduação têm importante papel na formação dos futuros professores, pois é a partir deles que a formação de um bom professor começa.

A escola tem sua parcela na formação de bons professores, pois a mesma deve se preocupar com a contínua formação de seus professores, e isso se dará através de reuniões de planejamento, grupos de estudos, o acompanhamento da prática e a oferta de formação continuada para seus professores, que como sabemos não podem parar de aprender e se qualificar para o exercício docente.

A formação continuada é o caminho mais seguro para se chegar a um perfil ideal de professor, logo essas formações devem ser ofertadas com seriedade e sempre buscando desenvolver competências que atendam a realidade na qual estão inseridos.

Os cursos de graduação na área docente devem valorizar o ensino aliando teoria à prática, para que assim os futuros professores saiam de suas formações preparados para o exercício docente e não se deparam com uma realidade que conhecem apenas no papel. Infelizmente o que as formações de professores oferecem hoje é uma teoria sem prática, e a didática que algo essencial no fazer docente fica por conta da leitura de estudiosos e teóricos, talvez isso explique a quantidade de professores despreparados em sala de aula nos dias atuais.

Os professores são profissionais inacabados e devem estar em constante formação, pois as demandas sociais mudam a cada dia e eles permanecem por um longo tempo, logo para atendê-las é necessário muito mais que um diploma de graduação, mas também uma formação reflexiva e crítica que consiga ver a educação além das páginas de um livro didático. O professor atual deve preparar os alunos não apenas para saber ler, escrever, ou para ingressar no mercado de trabalho, mas deve preparar o aluno para a vida, o que antes era papel dos pais hoje é compartilhado com a escola e consequentemente com os professores.

[...] a construção do conhecimento é uma trajetória coletiva em que o professor orienta, criando situações e dando auxilia, sem ser o especialista que transmite o saber, nem o guia que propõe a solução do problema. (Perrenoud, 2000, p.35)

Temos hoje na escola e nos professores a responsabilidade de preparar pessoas para o exercício de uma democracia crítica, o que tem se tornado cada vez mais difícil se conseguir, seja por falta de ajuda, por falta de vontade de muitos professores, pelas formações inacabadas ou por tantos outros motivos. O fato é que se queremos no futuro viver uma realidade diferente devemos ter um novo olhar para educação, para a formação dos professores, para o acompanhamento da família, e por fim, um novo olhar para os alunos.

\section{Resultados e Discussão}

O que se pode compreender de toda essa temática é que a partir de novas exigências educacionais que vêm surgindo com o desenvolvimento da sociedade como um todo, a relação do professor com o aluno e o modo de ensinar tem se modificado, configurando-se um desafio para esse profissional de educação, que por hora sentia-se preparado, pronto para atuar em sala de aula, e agora necessita usar de novas ferramentas metodológicas para atender a um público que vem se renovando junto com a sociedade.

Nessa jornada de conhecimento e transformação do ambiente escolar todos que compõe esse corpo precisam atuar juntos, o coordenador, nesse caso, será um maestro que pode guiar esses professores, para que a ação docente da prática seja como elemento de reflexão nesse momento de contínuo aprendizado; Os pais como auxílio na ajuda aos alunos; A sociedade por sua totalidade, pois é dela que parte as cobranças, mas na hora do apoio ele fica neutra; O sistema que não está preparado 
para gerir essa classe educacional tão importante para um bom desenvolvimento social, e claro, o professor, ele precisa estar ciente que ele é um provedor de conhecimento e precisa estar preparado para a docência, formando-se de maneira correta e crítica reflexiva, buscando participar sempre de formações continuadas para enriquecer suas aprendizagens científicas e numa perspectiva pedagógica estar sempre em comum acordo com a desenvolvimento social que circunda seu bom desempenho profissional.

É importante que essas reflexões aconteçam, para que haja um novo olhar por parte de todos para com o professor.

\section{Considerações Finais}

Ao concluir as leituras e fazer uma reflexão sobre o papel do professor para o desenvolvimento da sociedade percebese que muito ainda tem a se fazer na educação para vivermos em uma sociedade mais justa e igualitária, até mesmo a visão que temos de educação precisa mudar, pois muitos ainda pensam que o papel da escola é apenas formar pessoas para o mercado de trabalho, visão essa que ficou no passado e que muda a cada dia.

Para atender a todas as exigências precisa-se de professores que estejam preparados para os desafios que esse novo século nos impõe, e para isso muitas questões devem ser revisadas, como os salários, as formações, a presença da família lado a lado com o professor, a união da escola na ajuda a esse profissional que precisa de total suporte para desenvolver um trabalho de qualidade.

Para alcançar um perfil ideal para este século o professor também precisa de condições ideais de trabalho, só assim se sentirá motivado a vencer os desafios impostos por essa profissão tão nobre que é educar.

Muitos são os desafios, mas maiores serão as recompensas se todos se uniram para ajudar os professores a se adequarem a esse novo século e desenvolver competências que atendam às necessidades de alunos que precisam se preparar para a vida e não apenas para assumirem uma vaga de emprego.

Ser um professor com um perfil ideal é ter muito mais que conteúdos, é ter a capacidade de formar pessoas atuantes e úteis para a sociedade; é ter uma mente aberta para encarar as diferenças de forma igualitária e buscar entender o novo como um auxílio no desempenho do seu trabalho; é ter vontade de vencer os desafios mesmo diante de tantos problemas que a educação enfrenta a cada dia; é não ter medo de enfrentar o novo; é buscar se capacitar diante de tantas inovações, para entregar aos seus alunos sempre a metodologia acertada que seja eficaz na busca pelo aprendizado; é pensar numa educação inovadora e por fim, é ser professor do século passado ensinando alunos do século XXI.

As buscas por ser um bom profissional de educação são contínuas, visto que esses profissionais estão sempre em processo de adaptações a mudança da realidade, já que eles são os provedores, os agentes de transformação. Para que esse processo aconteça, é necessário que estes busquem estar sempre em movimento, numa constante formação, adaptando-se e inserindo-se no novo, que surge a todo momento, para que assim possam suprir as necessidades impostas pela sociedade para melhor atendê-las.

\section{Referências}

Antunes, C. (2010). A prática dos quatro pilares da Educação na sala de aula. Petrópolis: Vozes.

Almeida, V. D. (2012). A experiência em experiência: Saberes docentes e a formação de professores em exercício. Paco editorial.

Almeida, L. R. \& Placco, V. M. N. S. O. (2013). Coordenador pedagógico e a formação centrada na escola. Loyola.

Charlot, B. (2000). Da relação com o saber: elementos para uma teoria. Artmed.

Freire, P. (1996). Pedagogia da Autonomia: saberes necessários à prática educativa. Paz e Terra.

Freire, P. (1975). Pedagogia do oprimido. Paz e Terra. 
Research, Society and Development, v. 10, n. 7, e12310716356, 2021

(CC BY 4.0) | ISSN 2525-3409 | DOI: http://dx.doi.org/10.33448/rsd-v10i7.16356

Gil, A. C. (1994). Métodos e técnicas de pesquisa social. 4ed. Atlas.

Libânio, J. B. (2012). A Arte de Formar-se. Loyola, 2012 [Coleção FAJE]

Libânio, J. C. (2005). Educação Escolar: políticas, estrutura e organização. Cortêz.

Lakatos, E. M. \& Marconi, M. A. (1996). Técnicas de pesquisa: planejamento e execução de pesquisas, amostragens e técnicas de pesquisas, elaboração, análise e interpretação de dados. 3ed. Atlas.

Mercado, L. P. L. (1999). Formação continuada de professores e novas tecnologias. EDUFAL.

Moran, J. M. (1995). Novas Tecnologias e o Reencantamento do Mundo. Tecnologia Educacional. Vol. 23, n.126.

Nova escola. (2010). Edição 236, 01 de outubro | 2010 https://novaescola.org.br/conteudo/331/vinte-caracteristicas-professor-idea

Nóvoa, A. (1995). (Org.) Profissão professor. Portugal: Porto, 2. ed., 1995. Cúmplices ou reféns? Nova Escola. São Paulo: Abril; n. 162, p. 14-15, mai. 2003.

Nóvoa, A. (2002). Escola nova. A revista do Professor. Ed. Abril.

Nóvoa, A. (1997). Profissão professor. $2^{\text {a }}$ ed. Porto/Portugal: Porto Editora.

Perrenoud, F. (2000). Dez novas competências para ensinar. Tradução Ramos, P. C. Artes Médicas Sul

Piaget, J. (2007). Para onde vai à educação? José Olímpio.

Tardif, M \& Lessard, C. \& Lahaye, L. (1991). Os professores face ao saber-esboço de uma problemática do saber docente. Teoria \& Educação, Porto Alegre, n. 4.

Tardif, M. (2002). Saberes docentes e formação profissional. Vozes.

Unesco. (2015) Organização das Nações Unidas para Educação, Ciência e Cultura.l 